\title{
A 9-Year Follow-Up of Women and Men Reporting Pain: Results from The Swedish National Study Of Aging And Care - Blekinge
}

\author{
Lena Sandin Wranker ${ }^{1,2}$, Mikael Rennemark ${ }^{3}$, Johan Sanmartin Berglund ${ }^{1,4}$ and Sölve Elmståhl ${ }^{2}$ \\ ${ }^{1}$ Department of Health, Blekinge Institute of Technology, Karlskrona, Sweden \\ 2 Division of Geriatric Medicine, Department of Health Sciences Lund University, Sweden \\ ${ }^{3}$ Department of Psychology, Linnaeus University, Växjö, Sweden \\ ${ }^{4}$ Center of Competence, Blekinge County Council, Sweden
}

"Corresponding author: Lena Sandin Wranker, Department of Health, Blekinge Institute of Technology, Karlskrona, Sweden, Tel: +46708962509 I; E-mail: lena.sandinwranker@spray.se

Received date: April 03, 2016, Accepted date: June 15, 2016, Published date: June 22, 2016

Copyright: ( 2016 Wranker LS, et al. This is an open-access article distributed under the terms of the Creative Commons Attribution License, which permits unrestricted use, distribution, and reproduction in any medium, provided the original author and source are credited.

\begin{abstract}
Background and aim: Pain is common in older adults, but its relationship with ageing is unclear. The aim was to investigate pain among adults aged 72 years and older by means of a population-based sample followed for a period of nine years.

Methods: The Swedish National study on Aging and Care (SNAC) is conducted at four research centres. At SNAC-Blekinge (B), 609 (60.6\%) women and 396 (39.4\%) men were recruited and included from the baseline sample $(n=1,005)$. Re-examination was carried out on 328 participants, $204(62.2 \%)$ women and $124(37.8 \%)$ men. Pearson Chi-Square and T-test were used to compare groups. Locus of Control (LOC) was measured using a short version of the original health LOC scale. Relief from pain was analysed by logistic regression.
\end{abstract}

Results: At the follow-up investigation, 69/204 (33.8\%) women reported pain. Of the women who reported pain at baseline, $82 / 136(60.3 \%)$ stated that they were pain free. Fewer women reported pain with increasing age, Pearson Chi-Square $7.980, p<0.02$.

At the follow-up investigation, 27/124 (21.8\%) men reported pain. Of the men reporting pain at baseline, $44 / 58$ $(75.9 \%)$ stated that they were pain free. Low external locus of control (eLOC) were associated with relief from pain (OR 2.18, $\mathrm{Cl} 1.13-4.22), \mathrm{p}<0.02$. Mean age differences between the groups pain/no pain was found, $p<0.001$.

Conclusions: The number of women reporting pain decreased with increasing age. Pain may contribute to premature death. Relief from pain was higher for men compared to women, and low eLOC may be a contributing factor.

\section{Introduction}

Pain is a major health problem in Europe [1]. Although differences were observed between European countries, $40 \%$ had inadequate pain management [1]. Contradictory data have been published, where the prevalence of pain increases with age [2] or peaks in middle age and then declines again [3]. In Australia, the prevalence of pain among men was found to peak in the 65-69 year age group, while for women, it peaked in the 80-84 year age group [4]. The earlier misconception that pain is a normal consequence of aging may explain why pain in older adults has only recently received attention. Pain is common in older adults but the nature of this relationship with ageing is unclear. In a study of almost 3,000 individuals aged 50 years and over, the onset of widespread pain, independent of sex, was associated with a decrease in healthy ageing [5]. Adults with chronic pain are at increased risk for earlier mortality as well as developing age-related diseases prematurely and cognitive decline at younger age [6]. There is a lack of knowledge about how pain develops over time in the general population of older adults and, in addition, studies investigating factors associated with recovery from pain are sparse. In the population aged 60 years and over, the reported pain prevalence was about $55 \%$, and $64 \%$ of those reporting pain were women [7]. One explanation of the differences in reported prevalence could be that some studies have investigated special circumstances, such as arthritis [8] or knee and hip pain $[9,10]$, while others present the prevalence among patients in hospital or at a primary care centre [11].

Thanks to previous research, a large body of knowledge about healthy aging has been gathered. In general, older people are hindered by their symptoms rather than their disease [12], which indicates the importance of focusing on the experienced symptoms (for example pain) and perceived health instead of the diagnoses per se. Knowledge about how pain affects the aging population has improved over the past two decades $[13,14]$. Physical activity and sleep are important determinants of healthy aging, as well as psychological factors. It can be assumed that pain is also an important (negative) determinant.

Pain is an unpleasant sensory and emotional experience [15] but the factors underlying individual differences in pain response are not yet fully understood [16]. The experience of pain might be affected by biological, socio-cultural and psychological factors [17-20]. For example, in a number of studies, insomnia has been shown to be 
related to pain. Schuh-Hofer et al. found that one night of total sleep deprivation leads to a state of generalized hyperalgesia [21]. Financial status might also influence pain, as in Sweden, income differences in health care seeking behaviour favouring higher-income groups were observed among men, irrespective of age, and among older women [22].

As an example of psychological factors, Buckelew and colleagues [23] found that younger male patients with pain reported a stronger internal locus of control (iLOC) compared to older male patients who relied to a greater degree on others. Cano-Garcia and colleagues [24] found clusters that could be classified from the best to the worst adjustment to chronic pain, thus supporting the theoretical model of locus of control (LOC) patterns among a chronic pain population, proposed in 1982 by Wallston and Wallston [25]. As indicated by previous research the self-reported prevalence of pain seems to decrease with higher age but pain also increases the risk of premature death $[6,26]$.

Thus, the aim of this study was to investigate reported pain among older adults aged 72 years and older over time, as measured in a population-based sample followed for a period of nine years. Additional aims were to establish whether insomnia, financial situation, iLOC and external locus of control, (eLOC), were associated with pain relief in a representative sample of older women and men by means of multivariate models and to determine whether pain leads to premature death, using the T-test. The results are expected to be useful for preventing and treating pain.

\section{Method and Participants}

The study draws on the Swedish National Study on Aging and Care (SNAC)-Blekinge (B), approved by the Ethics Committee of the Medical Faculty at Lund University (LU 605, LU 744-00). The SNAC-B includes a representative sample of the population of older adults in the county of Blekinge. This sample is part of the longitudinal population based Swedish National Study on Aging and Care (SNAC), which investigates the patterns of health and living conditions of the Swedish population aged 60 years and older. The SNAC is conducted at four research centres in Sweden. In the present study, participants aged 72 years and older were recruited from the SNAC baseline sample.

A randomized selection was made from the population register. Potential participants were invited by letter to take part in the study. In the Blekinge centre, 2,312 individuals were invited to participate, of whom 1,402 (61\%) agreed. Reasons for non-participation (910 subjects) were lack of interest (83\%), illness (10\%) and could not be contacted (7\%). Of those who agreed to participate in the SNAC, 1,005 (age 72 years or older) were included in the present study.

Baseline data collection was carried out during the period 2001-2003. A total of 396 (39.4\%) men and 609 (60.6\%) women aged 72 years and older were included in the present study. Re-examination and testing were carried out on 328 individuals, 124 men and 204 women, during the period 2010-2012. Only individuals from the first data collection were included in the nine year follow-up investigation (Figure 1).

\section{Procedure}

Trained assessors carried out medical examination and testing in two sessions; each examination lasted about 3 hours. A release form allowing access to medical records was obtained from all participants.
All subjects provided both verbal and written consent to participate. A questionnaire was completed in the period between the two sessions. Those who agreed to participate but were unable to travel to the research centre were examined in their homes. In order to avoid systematically exceeding the nominal age, the tests were performed within a 12-week time interval ( 6 weeks before and six weeks after the $72 \mathrm{nd}$ birthday). The design and structure of the SNAC project were previously presented by Lagergren [27].

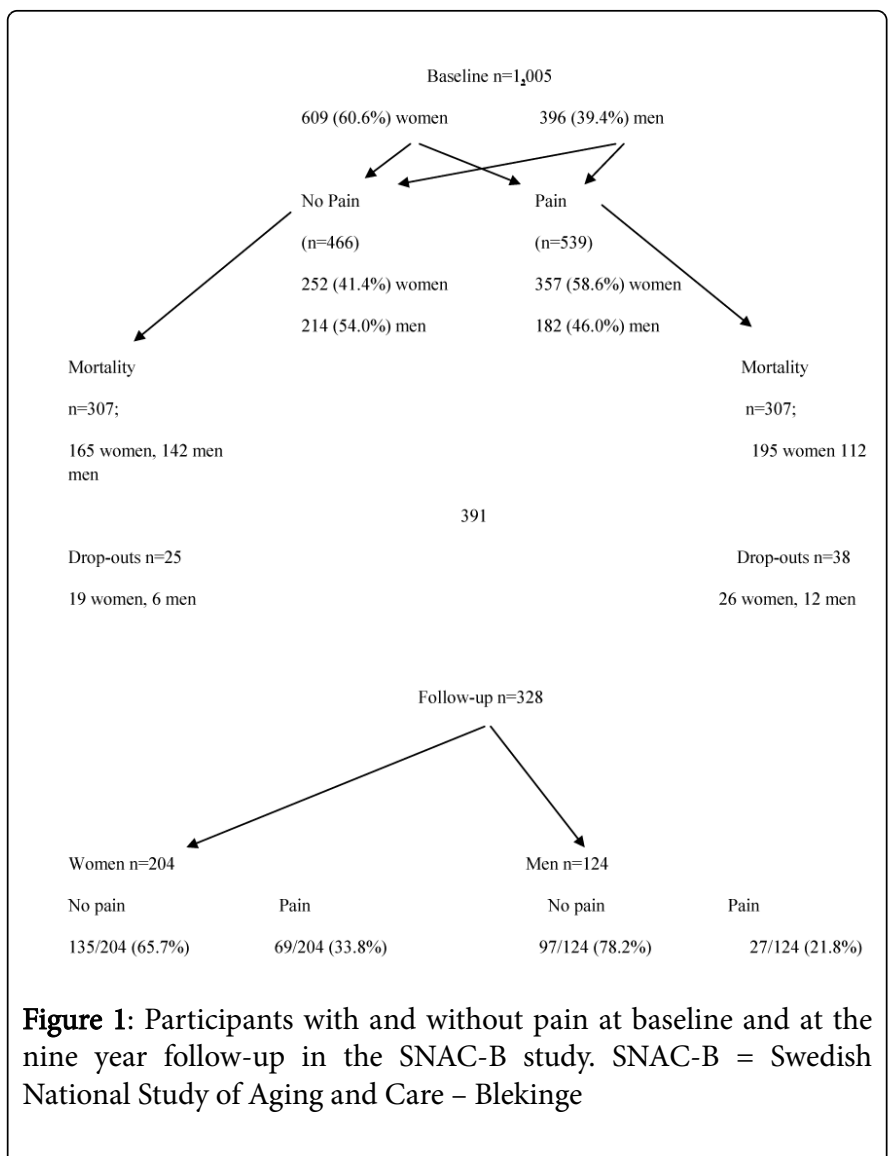

\section{Measures}

All participants completed a questionnaire, and the study protocols at both examinations were identical.

The independent variable pain was self-reported and based on the question: Have you had an ache/pain during the past 4 weeks? The response alternatives were 'Yes' and 'No'.

Sleep disturbances were dealt with by the question: Do you regularly suffer from insomnia? The response alternatives were 'Yes' and 'No'.

The question concerning the participants' financial situation, i.e., whether they had savings or a low economic status, was: If necessary, could you raise the sum of 14,000 SEK (about 2,000 USD) for unexpected expenses within one week? The response alternatives were 'Yes' and 'No'. This question from the SNAC database was based on a Swedish survey of income and living conditions [28].

LOC was measured using a short version of the original health LOC scale developed by Wallston [29]. The original version includes three subscales measuring one internal and two external control beliefs. The external LOC alternatives are"authority figures" and "circumstances 
Page 3 of 6

beyond one's control". The original scale has 18 items (6 items per subscale) and its validity in terms of measuring the concept of health LOC has been demonstrated. In the database used in the present study, three items from the iLOC subscale were employed: 1 . If I become ill, it is my own behaviour that determines how soon I recover, 2. I have control over my health and, 3. If I take care of myself, I can avoid illness. The range of (possible) scores was 3 - 15 points, with high scores indicating a higher level of iLOC. The Cronbach alpha for iLOC was 0.67 .

Three items from the eLOC subscale were used: 1 . My nearest and dearest are very important for whether I remain healthy or fall ill 2. My recovery from illness is usually because my nearest and dearest have cared for me well 3 . When it comes to my health, all I have to do is follow my doctor's orders. The range of scores was 3-15 points and high scores indicated a higher level of eLOC. The Cronbach alpha for eLOC was 0.52 .

\section{Statistical analysis}

The Pearson Chi-Square Test was used to investigate whether pain prevalence changed between baseline and the nine year follow-up. There is ample evidence in the literature to support the assertion that the multidimensional health locus of control (MHLC) subscales reliably measure individuals' health LOC beliefs, which is the construct they were designed to measure [25]. However, validity is an elusive concept and cannot be properly addressed without knowing 'validity for what purpose?' [29]. This study examined the relationship between
LOC orientation (internal or external LOC) and pain in a sample of older adults. The Cronbach's alpha was presented in order to reflect the internal consistency of the included items [30]. This value is dependent on the magnitude of the correlations between the items, as well as on the number of items in the scale. Because there were more than two response alternatives, the Cronbach's alpha should have been above 0.7 but as only three questions were included, a lower alpha value can be considered to indicate validity [30]. Cronbach's alpha was employed to describe the reliability of the LOC scales.

Multivariate logistic (forward) regression analyses were conducted to provide odds ratios (ORs) for the effect of insomnia, financial status and LOC on recovery from pain, as well as to study whether there was a relationship with pain relief when covariates were entered. T-test was used to compare differences in mean age between the groups pain/no pain. The level of significance of probability values ( $\mathrm{p}$-value) was set to $\mathrm{p}<0.05$ Missing data are reported in Figure 1 and indicated by (n) in all analyses. Data analysis was performed using the SPSS program, version 22.0 .

\section{Results}

Gender based differences in mean age between individuals with and without pain decreased with age and completely disappeared for men at the follow-up investigation (Table 1). Among women, T-test showed a significant difference in mean age if reporting pain or not, $(t=-17.37$; $\mathrm{t}>3.29, \mathrm{p}<0.00$ ), and the difference was about the same for men $(\mathrm{t}=-14.1 ; \mathrm{t}>3.29, \mathrm{p}<0.001)$.

\begin{tabular}{|l|l|l|l|l|}
\hline Mean age & Women With Pain & Women Without Pain & Men With Pain & Men Without Pain \\
\hline \multirow{3}{*}{ Baseline } & $81.8 \mathrm{yrs}$ & $83.5 \mathrm{yrs}$ & $80.4 \mathrm{yrs}$ & $82.0 \mathrm{yrs}$ \\
\cline { 2 - 5 } & $($ Std dev 6.38) & $($ Std dev 6.46) & $($ Std dev 5.64) & $($ Std dev 6.12) \\
\cline { 2 - 5 } & $(\mathrm{n}=357)$ & $(\mathrm{n}=252)$ & $(\mathrm{n}=182)$ & $(\mathrm{n}=214)$ \\
\hline \multirow{3}{*}{ 9years follow-up } & $86.7 \mathrm{yrs}$ & $87.3 \mathrm{yrs}$ & $86.9 \mathrm{yrs}$ & $86.8 \mathrm{yrs}$ \\
\cline { 2 - 5 } & $($ Std dev 5.38) & $($ Std dev 5.42) & $($ Std dev 4.89) & $($ Std dev 4.78) \\
\cline { 2 - 5 } & $(\mathrm{n}=69)(19.3 \%)$ & $(\mathrm{n}=135)(53.6 \%)$ & $(\mathrm{n}=27)(14.8 \%)$ & $(\mathrm{n}=97)(45.3 \%)$ \\
\hline
\end{tabular}

Table 1: Mean age among women and men with and without pain at baseline (72 years and older) and at the nine year follow-up (81 years and older) from the SNAC-B study; SNAC-B = The Swedish National Study on Aging and Care.

At baseline, 357/609 (58.6\%, C.I. 54.7 - 62.5) women reported pain and the corresponding number of men was $182 / 396$ (46.0\%, C.I. 41.1 50.9). The number of women with pain decreased to $69 / 204$ (33.8\%, C.I. 27.3 - 40.3) in the follow-up investigation. The number of men reporting pain in the follow-up measurement was roughly half the previous number, $27 / 124$ (21.8\%, C.I. 14.5 - 29.1).

The pain relief rate was high for women, $82 / 136$ (60.3\%, C.I. 52.1 62.5), but even higher for men, $44 / 58$ (75.9\%, C.I. 64.9 - 86.9) (see Figure 1).

At follow up, the number of individuals reporting pain during the past 4 weeks was about the same for women, 15/135 (11.9\%, 6.4 17.4), as for men, $13 / 97$ (13.4\%, C.I. 6.6 - 20.2). A multivariate forward logistic regression model for each sex was performed, with insomnia, financial status and locus of control (LOC) as covariates (Table 2).

Low eLOC scores were found to have significant odds ratios (OR 2.18 CI 1.13-4.22) for pain relief among older men (72 years and older) given that the odds for relief increased 1.18 times for each lower step on the eLOC scale.

\section{Discussion}

In this study, the results of a nine year follow-up of adults aged 72 years and older are presented, where the aim was to describe pain among older adults in the community based on age and sex. The median age differences between those who reported pain and those who reported no pain almost disappeared in the follow-up, which may be due to changes in age, but also to the effects of selective mortality.

Findings from this study, for both sexes, are significant differences in mean age if reporting pain or not indicating premature death among older adults with pain. Nevertheless, the results should be interpreted with caution, as few individuals attain the highest ages. If death is associated with pain, knowledge about relationship will be 
essential for the development of health policies for pain prevention and treatment.

A major goal of health policy should be to ensure that longer life is accompanied by better health and less disability. Further research should explore this issue.

\begin{tabular}{|l|l|l|l|l|l|l|}
\hline & \multicolumn{3}{|c|}{ Women } & \multicolumn{3}{c|}{ Men } \\
\hline Control variables & $\begin{array}{l}\text { odds } \\
\text { ratio }\end{array}$ & $95 \%$ C.I. & p-value & $\begin{array}{l}\text { odds } \\
\text { ratio }\end{array}$ & $95 \%$ C.I. & $\begin{array}{l}\text { p- } \\
\text { value }\end{array}$ \\
\hline $\begin{array}{l}\text { Insomnia } \\
\text { baseline }\end{array}$ & 1.4 & $\begin{array}{l}0.55 \\
3.58\end{array}$ & -0.48 & 21.2 & $0.58-781.40$ & 0.1 \\
\hline $\begin{array}{l}\text { Low education } \\
\text { level }\end{array}$ & 1.77 & $\begin{array}{l}0.61 \\
5.14\end{array}$ & -0.29 & 3.78 & $0.32-44.18$ & 0.29 \\
\hline Low iLOC & 1.16 & $\begin{array}{l}0.97 \\
1.38\end{array}$ & -0.11 & 1.19 & $0.80-1.76$ & 0.39 \\
\hline Low eLOC & 1.01 & $\begin{array}{l}0.97 \\
1.04\end{array}$ & 0.74 & 2.18 & $1.13-4.22$ & 0.02 \\
\hline
\end{tabular}

Table 2: The relationship between recovery from pain among women and men, 72 years and older, from the SNAC-B study $(n=123)$ : Logistic forward regression models illustrating the association between the independent variable eLOC and recovery from pain among women (Nagelkerke R square 0.08) and among men (Nagelkerke R square 0.35). SNAC-B = Swedish National Study of Aging and Care Blekinge; iLOC = internal locus of control; eLOC = external locus of control.

The number of individuals reporting pain declined with increasing age and was about a third (33.8\%) among women and around a fifth $(21.8 \%)$ among men. The occurrence of pain within the past four weeks was about the same for women, $15 / 135$ (11.9\%), as for men, $13 / 97$ (13.4\%). The relief rate was high for women, $82 / 136$ (60.3\%), but even higher for men, 44/58 (75.9\%), and low eLOC was associated with pain relief among the latter. The high mortality rate in the group that reported pain may have influenced these results, as the pain relief rate may not necessarily have been as high among those who had died. Our study, investigated two cross-sectional surveys of the same population (nine year follow-up), which selects survivors and more healthy individuals. Thus, co-morbidity and persistent pain could have been higher in the non-survival group. Time trends in Sweden indicates healthier older adults since an increase in the proportion of never hospitalized older adults has been noticed [31].

The finding that even among the oldest old, pain is more common in the female part of the population is in line with earlier studies [5,7]. However, as far as we can ascertain, no previous studies have investigated the occurrence of a new episode of pain or the rate of relief from pain in this age group. The findings should encourage reconsideration of the widely held belief that pain is a normal consequence of aging and therefore need not be addressed. The high relief rate among both women and men indicates that pain is not a consequence of growing older. The number of individuals reporting pain was lower in the follow-up and the difference was statistically significant among women.

The positive conclusion that many older people can become free of pain should be followed by the recommendation that sufferers should obtain adequate pain relief. Increased prescribing of various physical activities and a referral to a physical therapist or, if necessary, referral to an orthopedic technician would be desirable. Buprenorfin (patches), has been introduced as a new long-lasting, (7 days), pain relief treatment, that does not require dosage adjustment in the elderly. However, since the adverse event profile is the same as for other opioids it should not have affected the outcome significantly.

Previous studies have revealed that a significant proportion of such individuals do not receive appropriate treatment for their pain $[1,7]$. The reason for relief of pain with higher age remains unclear but could in some degree be due to a higher degree of acceptance.

A fair interpretation of the results must take some limitations into account. As the data are largely self-reported the risk of recall bias is ever present. Research personnel conducted the three hour medical examination both at baseline and at the follow-up investigation. This comprehensive survey entails the risk of fatigue in the participants, which may affect their responses. An opportunity to rest was however offered to safeguard the accuracy of the data. The definition of pain was based on whether the participants reported pain during the previous four weeks, which might have led to some misclassification, i.e., the inclusion of individuals with acute pain. However, there is no reason to believe that this distorted the results, as the procedure was identical nine years later. The reported prevalence of pain among older adults and the gender difference are consistent with findings from a study in the UK using the same question about pain during the previous four weeks [26]. Thomas and colleagues found a decline in prevalence of regional pains in the older age-groups [26].

The SNAC was developed for population-based longitudinal studies, but multidimensional assessment of pain can also be valuable in clinical trials and other types of longitudinal study. The SNAC-B respondents are considered representative of elderly people in Sweden regarding age, gender and quality of life. However, patients in everyday clinical practice differ from our sample [11]. The definition of pain used in this study does not separate site or cause. However, our study is population based thus we follow a randomized sample from the general population and not selected group of patients. Therefore, some age-related pain types, the most common one - arthrosis, are less prominent than would be the case if different pain types and locations were assessed separately. The consistence of our findings with the UK results [26] supports our result that pain decreases with age among the healthy general population.

There is ample evidence in the literature to support the assertion that the multidimensional health locus of control (MHLC) subscales reliably measure individuals' health LOC beliefs (which is the construct they were designed to measure) [25]. However, validity is an elusive concept and cannot be properly addressed without knowing 'validity for what purpose? [29]. This study examined the relationship between LOC orientation (internal or external LOC) and pain in a sample of older adults. The Cronbach's alpha was presented in order to reflect the internal consistency of the included items [30]. This value is dependent on the magnitude of the correlations between the items, as well as on the number of items in the scale. Because there were more than two response alternatives, Cronbach's alpha should have been above 0.7 but as only three questions were included, a lower alpha value can be considered to have validity [30]. In older men, a low eLOC score can be interpreted as either being pain free or receiving adequate pain relief. Today, pain management courses are mainly provided for younger adults. The goal of such courses is to reduce eLOC while strengthening iLOC by means of various therapies although it does not necessarily mean that high values on one of the factors causes low value on the other. Perhaps pain management 
courses should be included in the treatment strategies for older men. However, as the items were formulated by the research team and not by healthcare providers, it is important to take into account the actual situational potential for control, patients' perceptions and expectations of control as well as the expectations of healthcare providers when evaluating the results. Only by studying the complex interaction of these factors can we predict health behaviour and intervene effectively to enhance health.

The main question is the definition of pain, i.e., the experience of pain associated with actual or potential tissue damage or described in terms of such damage [15]. The reported pain could emanate from some part of the body, the body in general or the psyche. The strength of this prospective study is the fact that data were systematically collected prior to the decision to use them in the present study.

\section{Conclusion}

The present findings contribute some insight into aspects of life among elderly people faced by the challenging experience of pain. The average age of the group who report pain is lower compared to the group without pain indicating premature death. Besides revealing the number of older people who report pain and that a very large proportion of them can become pain free, a possible health factor may have been found, in that a low eLOC in men was associated with relief from pain.

\section{Acknowledgement}

The Swedish National Study on Aging and Care, SNAC (www.snac.org), is financially supported by the Swedish Ministry of Health and Social Affairs. We are grateful to the participants, as well as to the counties, municipalities and university departments involved. The present study was supported by the Centre of Competence, County of Blekinge and the Blekinge Research Council. We would also like to thank Claes Jogreus, School of Health Science, Blekinge Institute of Technology, Karlskrona, Sweden, for assistance with the statistics. The authors declares that there is no conflict of interest.

\section{References}

1. Breivik H, Collett B, Ventafridda V, Cohen R, Gallacher D (2006) Survey of chronic pain in Europe: prevalence, impact on daily life, and treatment. Eur J Pain 10:287-333.

2. Wolfe F, Ross K, Andersson J, Russell Ij, Herbert L (1995) The prevalence and characteristics of fibromyalgia in the general population. Arthritis rheum 38:19-28.

3. Andersson HI, Ejilertsson G, Leden I, Rosenberg C (1993) Chronic pain in a geographically defined population: studies of differences in age, gender, social class and pain localization. Clin J Pain9:174-182.

4. Blyth FM, March LM, Brnabic AJ, Jorm LR, Williamson M, et al. (2001) Chronic pain in Australia: a prevalence study. Pain 89:127-134.

5. Wilkie R, Tajar A, McBeth J (2013) The onset of widespread musculoskeletal pain is associated with a decrease in healthy ageing in older people: a population-based prospective study. PLoS One. 8:e59858.

6. Hassett AL, Clauw DJ, Williams DA (2004) Premature aging in fibromyalgia. Curr Aging Sci 8:178-185.

7. Wranker LS, Rennemark M, Berglund J (2016) Pain among older adults with gender perspective: findings from the SNAC study. Scand. J publ Health 44:258-263.

8. Otter SJ, Lucas K, Springett K, Moore A, Davies K, et al. (2010) Foot pain in rheumatoid arthritis prevalence, risk factors and management: an epidemiological study. Clin Rheumatol 29:255-271.
9. Andersen RE, Crespo CJ, Ling SM, Bathon JM, Bartlett SJ (1999) Prevalence of significant knee pain among older Americans: results from the Third National Health and Nutrition Examination Survey. J Am Geriatr Soc 47:1435-1438.

10. Christmas C, Crespo CJ, Franckowiack CK, Bathon JM, Barlett SJ, et al. (2002) How common is hip pain among older adults? Results from the third national health and nutrition examination survey. J Fam Pract 51:345-348.

11. Konstantinou K, Dunn KM, Ogollah R, Vogel S, Hay EM (2015) ATLAS study research team. Characteristics of patients with low back and leg pain seeking treatment in primary care: baseline results from the ATLAS cohort study. BMC Musculoskelet Disord 4:16:332.

12. Fagerström C, Holst G, Hallberg IR (2007) Feeling hindered by health problems and functional capacity at 60 years and above. Arch Gerontol Geriatr 44:181-201.

13. Herr K, Titler MG, Schilling ML, Marsh JL, Xie X, et al. (2004) Evidencebased assessment of acute pain in older adults: current nursing practices and perceived barriers. Clin J Pain 20:331-340.

14. Wranker LS, Rennemark M, Berglund J, Elmståhl S (2014) Relationship between pain and Quality of Life-Findings from the Swedish National Study on Aging and Care - Blekinge study. Scand J Pain 5:270-275.

15. Merskey H, Bogduk N (1994) Classification of Chronic Pain, Second Ed. IASP Task force on Taxonomy. Part III: Pain Terms, A current list with definitions and notes on usage. IASP Press, Seattle 209-214.

16. Angst MS, Phillips NG, Drover DR, Tingle M, Ray A, et al. (2012) Pain sensitivity and opioid analgesia: a pharmacogenomic twin study. Pain 153:1397-1409.

17. Ackerman LN, Bennet KL, Osborne RH (2011) Decline in health-related quality of life reported by more than half of those waiting for joint replacement surgery: a prospective cohort study. BMC Musculoskeletal disord 12:108.

18. Bilotta $C$, Bowling A, Nicolini $\mathrm{P}$, Casè A, Vergani C (2012) Quality of life in older outpatients living alone in the community in Italy. Health Soc Care Community 20:32-41.

19. Enkvist A, Ekström H, Elmståhl S (2012) Life satisfaction (LS) and symptoms among the oldest -old: Results from the longitudinal population study called Good Aging in Skåne (GÅS) Arch Gerontol Geriatr 54:146-150.

20. Gureje O, Von Korff M, Kola L, Demyttenaere K, He Yanling, et al.(2008) The relation between multiple pains and mental disorders: Results from the World Mental Health Surveys. Pain 135:82-91.

21. Schuh-Hofer S, Wodarski R, Pfau DB, Caspani O, Magerl W, et al. (2013) One night of total sleep deprivation promotes a state of generalized hyperalgesia: a surrogate pain model to study the relationship of insomnia and pain. Pain 154:1613-1621.

22. Agerholm J, Bruce D, Ponce de Leon A, Burström B (2013) Socioeconomic differences in healthcare utilization, with and without adjustment for need: an example from Stockholm, Sweden. Scand J Public Health 41:318-325.

23. Buckelew SP, Shutty MS Jr, Hewett J, Landon T, Morrow K, et al. (1990) Health locus of control, gender differences and adjustment to persistent pain. Pain 42:287-294.

24. Cano-García FJ, Rodríguez-Franco L, López-Jiménez AM (2013) Locus of control patterns in headaches and chronic pain. Pain Res Manag 18:e48-54.

25. Wallston KA, Wallston BS (1982) Who is responsible for your health: The construct of health locus of control. In G. Sanders \& J Suls (Eds.) Social Psychology of Health and Illness. Hillsdale, NJ Lawrence Erlbaum \& Associates 65-95.

26. Thomas E, Peat G, Harris L, Wilkie R, Croft PR (2004) The prevalence of pain and pain interference in a general population of older adults: crosssectional findings from the North Staffordshire Osteoarthritis Project (NorStOP). Pain 110:361-368.

27. Lagergren M, Fratiglioni, Rahm Hallberg I, Berglund J, Elmståhl S, et al. (2004) A longitudinal study integrating population, care and social 
Citation: Wranker LS, Rennemark M, Berglund JS, Elmståhl S (2016) A 9-Year Follow-Up of Women and Men Reporting Pain: Results from The Swedish National Study Of Aging And Care - Blekinge. J Aging Sci 4: 153. doi:10.4172/2329-8847.1000153

Page 6 of 6

services data. The Swedish National Study on Aging and Care (SNAC) Aging: Clinical \& Experimental Research 16:158-168.

28. Statistics Sweden (SCB) (2004) Living conditions. Ill health and care in the country. (In Swedish). Ämnesområde: Levnadsförhållanden, tabell: Ohälsa och vård (ULF) I riket efter ålder, kön och hälsoindikator. År 1980-2003.

29. Wallston KA, Wallston BS, DeVellis R (1978) Development of the multidimensional health locus of control (MHLC) scales. Health Education Monographs 6:160-170.
30. Streiner DL, Norman Gr (2000) Health measurement scales. A practical guide to their development and use. Sec. ed. Oxford med. Publ ISBN 019 2626701 (Pbk)

31. Karampampa K, Andersson T, Drefahl S, Ahlbom A, Modig K (2014) Does improved survival lead to a more fragile population: time trends in second and third hospital admissions among men and women above the age of 60 in Sweden. PLoS One 9:e99034. 